\title{
What role should the commercial food system play in promoting health through better diet?
}

\author{
(C) $(\mathcal{\Theta} \Theta$ OPEN ACCESS
}

Martin White and coauthors consider that the commercial food system has the potential to show leadership and support for dietary public health, but systemic change is needed first and this is likely to require governmental action

\section{Martin White professor of population health research ${ }^{1}$, Emilie Aguirre Earl B Dickerson fellow ${ }^{2}{ }^{3}$, Diane T Finegood professor ${ }^{4}$, Chris Holmes independent consultant ${ }^{5}$, Gary Sacks associate professor $^{6}$, Richard Smith professor of health economics ${ }^{7}$}

${ }^{1}$ Centre for Diet and Activity Research, MRC Epidemiology Unit, Institute of Metabolic Sciences, University of Cambridge, UK ; ${ }^{2}$ University of Chicago Law School, Chicago, IL, USA ; ${ }^{3}$ Harvard Business School, Boston, MA, USA; ${ }^{4}$ Morris J Wosk Centre for Dialogue, Simon Fraser University, Vancouver, BC, Canada; ${ }^{5}$ Aldershot, Surrey, UK; ${ }^{6}$ Global Obesity Centre, Deakin University, Burwood, VIC 3125, Australia; ${ }^{7}$ College of Medicine and Health, University of Exeter, Exeter, UK

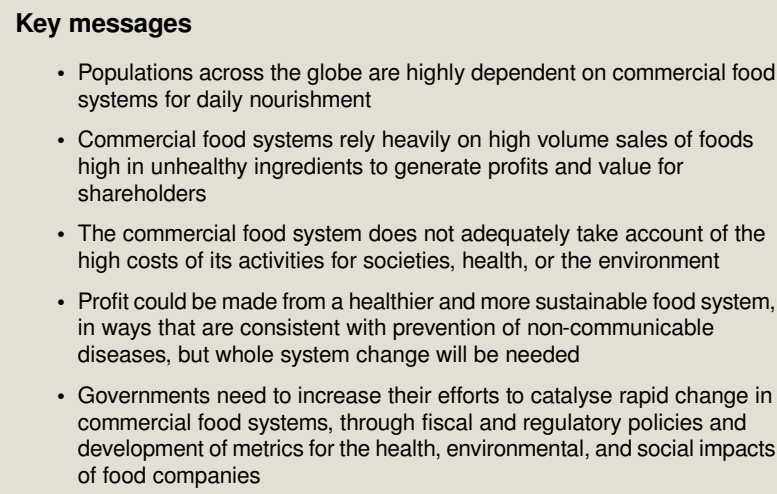

The commercial food system is of increasing concern to those responsible for improving population health. ${ }^{1}$ The transition in global nutrition is rapidly changing agricultural practices and increasing the consumption of nutritionally poor processed foods, which are associated with increases in non-communicable diseases. ${ }^{2}$ The growth of childhood obesity, in particular, continues largely unchecked, risking enormous burdens of future disease, health system costs, ${ }^{3}$ and intergenerational inequalities. ${ }^{4}$ A number of aspects of nutritionally poor processed foods, especially ultra-processed foods, are unhealthy (eg, excess salt or sugar). ${ }^{2}$ The mechanisms that lead to associations between processed foods and poor health remain largely unknown. ${ }^{5}$
Processed foods have some advantages-for example, their longer shelf life and convenience-and they may not inherently need to be unhealthy. Nevertheless, how to achieve healthier processed foods remains unclear.

Food processing, and associated marketing, adds value to raw ingredients ${ }^{6}$ and is a key driver of profits for the commercial food system. Large, and especially publicly listed, food companies operate in an economic environment that demands continual growth of profits. This drive for profits leads to a range of emergent behaviours, such as aggressive marketing, the avoidance of regulation that could impede profits (eg, through lobbying), and the generation of huge external health, social, and environmental costs associated with the high volume sales of processed foods. These behaviours amplify the direct adverse effects of processed foods and result in poor alignment between commercial food production, environmental sustainability, societal wellbeing, and population health goals. ${ }^{7}$ This imbalance is unsustainable and needs urgent attention. The syndemic crises of climate change and global obesity ${ }^{8}$ need to be treated as emergencies now to avoid catastrophic costs and consequences for future generations.

In this article, we examine two questions. How can social, public health, and sustainability goals achieve parity with profit in the commercial food system? And, what leadership is needed to support this challenge globally? Although we briefly discuss the commercial food system as a whole, given the breadth, scale, 
and complexity of the system, our main focus is on the elements closer to consumers (manufacturing, retailing, and food service).

\section{Commercial food systems, diet, and health}

Our tastes and desires for foods are both physiologically driven and culturally embedded within societies. ${ }^{9}$ Dietary risks are among the greatest predictors of disease burden, leading to increased incidence and mortality from non-communicable diseases. These dietary risks include foods high in energy, salt, or added sugar and diets low in fruits, vegetables, legumes, nuts, seeds, and whole grains. ${ }^{10}$ Commercial food systems must, therefore, be considered one of the most important influences on population health globally. ${ }^{11}$

The commercial food system delivers largely affordable food to whole populations and has become vital to national economies, providing considerable employment and contribution to export trade. ${ }^{12}$ Global agricultural trade is valued at around $\$ 1 \mathrm{tn}(£ 0.78 \mathrm{tn}, € 0.88 \mathrm{tn})$ and food retail sales at around $\$ 4 \mathrm{tn}$ annually. ${ }^{13}$ The commercial food system produces sufficient food to adequately nourish the global population of around 7.5 billion but has two key defects.

Firstly, global output is heavily skewed towards processed foods, which deliver the greatest profits but are nutritionally inadequate and potentially harmful. ${ }^{14-16}$

Secondly, distribution of food products is uneven, resulting in substantial inequalities in physical and economic access to healthy and nutritious foods. ${ }^{12}$ Thus in many parts of the world people remain undernourished, yet, often in the same countries, people overeat affordable, energy dense foods and have associated chronic non-communicable diseases, leading to a "double burden" of malnutrition. ${ }^{17}$

The drive to increase production of food calories to feed the world's growing population over the past 70 years ("calorie fundamentalism") has been criticised ${ }^{18}$; globally we produce enough food energy but insufficient essential nutrients to ensure healthy diets. This challenge will be compounded by predicted global population growth over the next 50 years; it simply will not be viable, owing to the costs to the environment, health, and societies, to expand production based on dietary energy requirements alone.

\section{Small retailers and multinational companies}

All parts of commercial food systems are interconnected through supply and value chains, trade, and integration within large, often multinational, companies. Many multinational companies have broad portfolios, including both relatively healthy and unhealthy foods. The overall balance, however, is in favour of highly processed foods, the distribution of which is growing, especially in low and middle income countries. ${ }^{14}$ Although multinational companies command large market shares for specific foods or in particular sectors (eg, grocery retailing), the much larger numbers of smaller enterprises are also critically important in food provision, driving industry innovation and growth. For example, although the largest fast food chain in the UK commands a significant market share, it has just 1200 outlets compared with, for example, 10500 independent fish and chip shops $^{19}$ and a total of around 64000 independent takeaways across the UK. ${ }^{20}$

Multinational food companies have been increasingly criticised for their focus on maximising short term profits from less healthy food products, their negative effects on health and the environment, and their manipulation of markets and unduly influencing consumers. All these factors together shape policy and public opinion in relation to non-communicable disease prevention. ${ }^{21}$

Within the commercial food system a common pattern of "corporate political activities" aimed at influencing policy and public opinion has emerged. These activities are also seen in other "harmful commodity industries"-for example, tobacco, alcohol, and gambling. ${ }^{22}$ This pattern includes framing information to suit corporate objectives (including manipulation of science); lobbying and providing financial incentives to policy makers; building pro-industry constituency among policy makers, community groups, and health organisations; deploying legal strategies to oppose public health measures; extensive use of voluntary industry codes of practice to avoid government regulation; and efforts to fragment and destabilise groups likely to counter industry arguments. ${ }^{23}$

High profile examples of the influence of the food industry include efforts to change food labelling regulations in Europe ${ }^{24}$ and to repeal health related food taxes (eg, the soda tax in Cook County, Chicago, Illinois, USA and the Danish fat tax). ${ }^{25}$ The range of corporate political activities presents huge challenges for public health and is an important barrier to progress towards a healthier, more sustainable, and equitable food system.

\section{Complex and adaptive}

Commercial food systems encompass huge, complex, and interdependent networks of entities involved in agriculture and fisheries, food processing and production, storage and distribution, wholesaling and retailing, and preparation and marketing of raw, processed, and ready to eat foods. They are underpinned by global and national logistics, finance, trade agreements, and regulatory frameworks. ${ }^{26}$

To understand the commercial food system, it is helpful to view it as a set of inter-related complex adaptive systems. These systems are unpredictable, self-organising, and display behaviour patterns that result from interactions within the whole system but are not necessarily predictable by the behaviours of component entities. ${ }^{27}$ Such systems respond to external stimuli, such as new regulations, but readily adapt and achieve a new equilibrium, developing new structures, rules, and behaviours.

Complex adaptive systems tend to be governed by simple "rules" that lead to emergent properties. For example, supermarkets generally abide by an implicit, self-imposed simple rule-namely, that shelves must be plentifully stocked because consumers make a high proportion of purchasing decisions in front of shelves. This rule retains customers and drives sales but also creates logistic challenges that can result in overstocking and the emergent property of waste, especially of fresh produce. $^{28}$

An example of the food system adapting is the emerging commercial response to the UK's soft drinks industry levy, which was introduced in 2018. This levy applies a graded tax structure to soft drinks, with three tiers according to sugar levels: higher tier ( $£ 0.24 / \mathrm{L}$ for drinks with $>8 \mathrm{~g}$ of sugar/100 mL), lower (£0.18p/L for drinks with 5-8 g/100 mL), and no levy (for drinks with $<5 \mathrm{~g} / 100 \mathrm{~mL}$ ). Manufacturers of higher sugar drinks can choose not to change their drinks and absorb the cost or pass it on to customers by increasing prices; reduce sugar content to avoid the levy; or make other changes, such as diversifying their product ranges and the mix of product volumes and prices. All these responses have been seen since the announcement of the levy, yet the pattern of reactions was not predictable. ${ }^{29}$ Furthermore, change is continuing, accompanied 
by extensive marketing, ${ }^{30}$ indicating that the industry is continually testing many strategies in a quest to find the "sweet spot"-a new equilibrium where they maintain profits, comply with the law, and satisfy customers, albeit with a different commercial offer.

\section{Achieving growth}

The commercial food system has achieved continual economic growth through a range of actions: increased agricultural productivity reducing the cost of inputs; increased processing that simultaneously reduces the costs of production and distribution, lowers prices, and increases palatability and convenience of foods to consumers ${ }^{31}$; intensive and targeted marketing of foods with the greatest added value from processing $^{32}$; and increased economies of scale, consolidation, and extension of markets across nations. Economies of scale have been achieved through acquisitions, mergers, vertical and horizontal integration across the supply chain, proliferation of multinational companies, and using low wage economies (fig 1 and table 1$){ }^{11}$

Highly processed foods are palatable and satisfy human taste for salty and sweet foods. ${ }^{9}$ Despite their convenience, palatability, longer shelf life, improved food safety, endless choice, and affordability for consumers, ${ }^{33}$ highly processed foods are widely criticised for not contributing to a healthy diet. ${ }^{34}$ Aggressive marketing of such foods, often accompanied by health and nutrition claims (for example, "high in vitamins") that can obscure potential harms, drives and distorts consumer demand. ${ }^{35}$ Processed foods thus present a dilemma for public health, food policy, and consumer choice.

Recent growth in the sales of processed food, especially soft drinks, in low and middle income countries has been extraordinarily rapid. ${ }^{36}$ In many countries, a small number of food companies and retailers hold substantial economic power, owing to their size and the collective efforts of their trade associations. ${ }^{37}$ This power translates into substantial political influence nationally and internationally. ${ }^{1}$ Where the profitability of such companies is reliant on high volume sales of processed foods, their influence is often in direct conflict with health and sustainability efforts. In such circumstances, profits usually come first, resulting in food governance and public health policy that does not adequately balance public and commercial interests. ${ }^{22}$ Critically, the commercial food system does not adequately account for external costs, such as the environmental effects of intensive farming and food processing, the social costs of relying on low wage economies, and the effect on health of overconsumption of foods high in unhealthy ingredients and low in healthy ingredients (fig 1 and table 1 ) ${ }^{37}$ Food prices are therefore often artificially low, particularly for less healthy foods and those that have greater cost to the environment. ${ }^{38}$

\section{Healthier, more sustainable, yet commercially viable food systems}

When a market generates artificially low prices that do not account for environmental, social, and health externalities, government intervention is necessary. Furthermore, while food companies pursue profits through sales of unhealthy foods, they will maintain efforts to ensure that the regulatory environment favours the status quo. ${ }^{39}$ In this case, governments will need to do more to limit the influence of companies on health policy_for example, through trade agreements, regulation of advertising, fiscal policies, mandating nutrition labelling and transparency on food ingredients, and, possibly, use of competition laws. Advocacy groups, health professionals, and consumers will need to do more to recognise and counter unacceptable commercial tactics and encourage greater transparency of policy making processes and decisions (table 1).

Commercial food companies can voluntarily shift their focus towards expanding the market for healthier and more sustainable foods, while reducing the availability of less healthy foods. This shift would require a significant will to change as well as technical and business model innovations within commercial food systems (fig 2). The challenges of incorporating a larger proportion of healthy ingredients into shelf stable foods are considerable, but companies that can successfully overcome them should attain significant competitive advantage.

Although the predominant economic model of the commercial food system is poorly aligned with social, health, and environmental goals, recognition of this challenge and an appetite for change are emerging. Much of this effort is peripheral, such as the development of corporate social responsibility initiatives, rather than involving change in core business models.

Small but growing movements are emerging, such as impact investing and alternative "social" business models. ${ }^{40}$ Some of these alternative models use full cost accounting based on the triple bottom line, which proportionally or equally weights profit, people (social good), and the planet (environment). ${ }^{41}$ These models also include community interest companies and "B corporation" certification, which requires companies to pursue public benefit in conjunction with profit. ${ }^{42}$ The drive for such social purpose generally focuses on social or environmental causes, such as workers' rights and carbon reduction, and rarely on health. Thus certified B corporations can include companies that are famous for their environmental and social credentials but market unhealthy food products. ${ }^{42}$ If health externalities were included in B corporation certification criteria, this would offer a new lever for change.

Much of this pro-social commercial activity has been dismissed by critics as unenforceable, as green or health washing, or as failing to demonstrate a meaningful commitment by industry to reduce its untenably high external costs. ${ }^{43}$ As things stand, trends are in the wrong direction, with the highest profits globally coming from unhealthy, processed food..$^{44}$ Increasing evidence shows, however, that companies that place more emphasis on social goals can outperform competitors over the long term ${ }^{45}$ and that healthier foods are now driving sector innovation and growth. Indeed, there is some evidence that offering consumers healthier food has commercial potential, both in grocery retailing and for ready to eat takeaway or fast food (boxes 1 and 2). Whether this will also translate more widely into improved healthiness of food and associated sales remains to be seen. 


\section{Box 1: Potential for healthier grocery retailing}

Supermarkets range from small, local stores with thousands of product lines to mega stores with tens of thousands of products. The nature of the business and the possible changes at these different levels vary considerably. Much of the food available in supermarkets is highly processed and of poor nutritiona quality.$^{14}$ But, is all processed food bad? And, what evidence is there that manufacturers and supermarkets can produce and promote healthier alternatives? Although overall trends are worrying, they conceal a range of nutritional values; not all packaged foods are nutritionally poor. For example, $83 \%$ of "convenience foods" in Australia and New Zealand were eligible to carry health claims according to their nutrient profile.$^{46}$ In a study in the UK, although the profile was poor overall, one fifth of ready meals available in supermarkets were low in fat, saturated fat, salt, and sugar, and two thirds of these were labelled as "healthier" ready meals. ${ }^{47}$

In response to consumer and government pressures, supermarkets have introduced policies to restrict less healthy foods and promote healthier food-for example, by limiting "junk foods" at checkouts. ${ }^{48}$ Supermarket retailers in the US have also indicated some interest in healthier food retailing, but their willingness is constrained by perceived consumer demand, product availability, and price points. Further constraints include the complex competitive arrangements whereby strategic placement of products in supermarkets is governed by "listing" or "slotting" fees and dominated by industry "category captains." ${ }^{49}$

The Food Foundation is an independent UK think tank aiming to stimulate a healthier food system. Its flagship initiative, "Peas Please," aims to reverse the decline in vegetable consumption in the UK by seeking company pledges to achieve goals that could increase consumption. ${ }^{50}$ Historically, compliance of food companies with voluntary pledges has been poor (eg, in the UK government's public health responsibility deal),${ }^{51}$ except for salt reduction during the early 2000 s, which was a concerted effort by non-governmental organisations and government and seems likely to have resulted in health benefits. ${ }^{52}$ Voluntary actions by commercial food companies offer valuable publicity and opportunities for corporate social responsibility, but further evaluation is needed to understand better why some voluntary pledges affect population diet while others fail to deliver meaningful change.

\section{Box 2: Potential for healthier eating out}

Eating out has increased considerably over recent decades. ${ }^{53}$ Food prepared out of the home tends to be less healthy than food prepared at home, and its consumption has been associated with higher energy, saturated fat, and salt intakes and excess body mass..$^{545}$ In the UK, more than a quarter of adults and one fifth of children eat out more than once a week, and one fifth of both adults and children eat takeaway meals at home once or more a week ${ }^{56}$ With the ability to order online and continued expansion of the sector, these trends seem unlikely to be reversed in the short term. So, what scope is there for improving the nutritional quality of food eaten outside the home?

Research has focused mainly on the calorie content of food eaten outside the home. Recent papers in TheBMJ have illustrated this focus in the UK ${ }^{57}$ and six other middle and high income countries ${ }^{58} \mathrm{~A}$ range of interventions has been proposed and evaluated. ${ }^{5960}$ Foremost among these have been interventions that mandate calorie labelling on menus or at point of sale to help consumers make informed choices. ${ }^{61}$

A potentially more powerful action with greater effects on the population is to stimulate reformulation within the sector. ${ }^{62}$ Structural interventions such as the promotion of smaller portion sizes using packaging or tableware, ${ }^{63}$ adaptations to food dispensers (such as salt shakers that deliver less salt) in takeaways, ${ }^{64}$ and levies on the price of less healthy foods in restaurants ${ }^{65}$ have also been shown to promote healthier purchases, consumption, or diets. A growing number of companies now combine the convenience of home delivery with providing all the ingredients needed to prepare healthier meals in recipe boxes. These boxes are limited in their reach and profitability but could be scaled up to have a greater effect on the health of the population, although their effects on the environment will need to be carefully assessed. All such interventions could, without too many problems, be led by industry without external regulation or, in the absence of action, could be subject to legislation.

Accompanying this emerging market for healthier food products is an increase in the financing and incentivising of healthy food ventures. For example, venture capital investment in early stage healthier start-up companies is increasing. Multinational companies are creating their own in-house venture capital arms to deploy early stage investments and are also taking part in later stage acquisitions of healthier food companies to generate greater innovation and growth. These trends could expand the market for healthier food, although there is no guarantee that brands will maintain their healthy credentials once acquired. ${ }^{66}$ Bolstered by shifting millennial consumer preferences towards healthier foods-in particular, in higher income groups ${ }^{67}$ multinational companies could continue to expand further into healthier offerings, leveraging their commercial expertise, economies of scale, robust supply chains, and distribution channels to ensure profitability. Whether, and how, these trends are harnessed to improve diet, especially for lower income consumers, may have substantial implications for the global food supply and population health.

To effect meaningful dietary change in populations requires structural and system-wide action. Some food company executives have stated that they prefer regulation to voluntary change as then all competitors must follow the same rules. ${ }^{68}$ Regulation in conjunction with commercial innovation and appropriate tax and incentive structures for unhealthy and healthy foods, respectively, supported by voluntary actions, could enable the commercial food system to move more rapidly towards supplying healthy foods. ${ }^{69}$ Such a change is likely to require a cultural adjustment, in which companies place similar weight on social, health, and environmental goals as they do on profits.

\section{Implications for policy, practice, and research}

Change within the food industry will depend on economic, regulatory, and political factors, shifting public attitudes, and willingness of corporations to accept this change. The pursuit of social, health, and environmental goals together with economic goals will also require cultural and organisational change within companies. ${ }^{70}$ Viewing the commercial food sector as a complex adaptive system helps us to understand how it may be shaped in the interests of population health and suggests ways to intervene. ${ }^{27}$ Possible interventions range from achieving a fundamental change in approach (most difficult but having the greatest effect) to changing system substructures (easier but less effective). ${ }^{71}$ The kinds of interventions proposed in the UK's childhood obesity plan (eg, mandating calorie labelling and restricting price promotions for unhealthy foods $)^{72}$ seek leverage at the substructural level and are thus relatively weak levers for system change, although they may act synergistically to be more powerful. Evaluation of multiple synergistic actions will add vital new evidence.

Governments will need to act as both catalyst and regulator. ${ }^{73}$ Catalytic activities include information brokerage, coordination, and mobilisation of resources. These activities need to be supported by accountability systems to better promote company valuation beyond profit, which in turn requires change in accounting practices and improved metrics for measuring social, health, and environmental impacts, which are currently being explored. $^{74}$

Governments can help to develop metrics and incentivise or mandate their use - for example, through securities or corporate law. Examples of accountability systems include those developed by the Access to Nutrition Foundation, which assesses the progress of major food companies towards healthier and more transparent product portfolios. ${ }^{75}$ Another example is the INFORMAS initiative (International Network for Food and Obesity/Non-communicable Diseases Research, Monitoring and Action Support), which offers tools for governments and civil society to benchmark food environments globally. ${ }^{76} \mathrm{~A}$ global "framework convention on healthy and sustainable food systems" (using the model of the WHO Framework Convention on Tobacco Control) ${ }^{77}$ with which national governments would be required to comply, would provide a legal basis to drive action by all sectors and could powerfully underpin such tools. ${ }^{8}$ Achieving closer alignment between business and public health will require a major cultural shift. ${ }^{78}$ Coproducing solutions to 
public health challenges with businesses carries risks and also benefits. Creating "safe spaces" to negotiate and agree outcomes using strong governance frameworks will be important. This would be aided by a common language for these discussions, agreeing and setting clear expectations, building trust, and identifying opportunities for mutual learning. ${ }^{79}$ One stepping stone to this goal would be to develop a shared understanding of what a healthy, vibrant, and sustainable commercial food system looks like-namely, one that balances and optimises outcomes for the environment, people, and profit. ${ }^{80}$ The discussion started to generate UK government's forthcoming national food strategy, which involves deliberative events with citizens,${ }^{81}$ could provide such a template. ${ }^{82}$

To achieve such closer alignment of commercial and public health goals will require strong leadership from governments and international organisations. It will also require some bravery, humility, and willingness to change from both public health and commercial stakeholders. Progress is likely to be limited while the relation between public health and the commercial food system, and processed food companies in particular, remains adversarial and a huge imbalance of power exists. Governments need to recognise this imbalance of influence on the policy process and ensure a more appropriate balance of public and commercial interests in policy making that affects health. ${ }^{4}$ They then need urgently to drive change towards healthier commercial food systems to reverse costly global trends in

non-communicable diseases and their disastrous consequences for intergenerational inequalities in diet and health. ${ }^{4}$ To achieve the pace of change in the food system needed to deal with syndemic climate and obesity emergencies will require commitment of the food industry to a new business model, in which unsustainable growth is replaced by commitments to long term business value, people, health, and the environment. ${ }^{38}$

Interdisciplinary research should have a pivotal role in setting the agenda for this change. Research is urgently needed to understand the potential of food systems to achieve change that aligns with population health and sustainability goals. Important unanswered questions are set out in table 1 together with key challenges. The food industry needs to contribute to such efforts, but it will be vital to ensure that, in doing so, conflicts of interest arising from its potential for commercial gain are managed. Frameworks to guide governance of interactions between researchers and commercial organisations are being developed. ${ }^{83} 84$

Contributors and sources: MW conceived the idea for the article. All authors contributed to developing the arguments, researched the literature, helped to draft the manuscript, and approved the final version. MW is the guarantor. The article is based on our collective professional experience and a review of published material in the public domain. MW is grateful to Anna Taylor, chief executive of the Food Foundation, for extensive and insightful discussions about food system challenges and solutions. MW leads publicly funded research on food systems and public health at the University of Cambridge. EA holds a degree in sociology from Princeton and degrees in law from Harvard and Cambridge. She is presently a doctoral candidate in Health Policy and Management at Harvard Business School and Harvard Graduate School of Arts and Sciences examining how for-profit companies pursue social and economic goals simultaneously. DTF holds degrees in chemical and biomedical engineering, physiology, and biophysics. Through her various leadership roles, including as inaugural scientific director of the Canadian Institutes of Health Research's Institute of Nutrition, Metabolism and Diabetes, she has developed an academic interest in public-private partnerships and systems approaches to complex problems. After a 15-year commercial career in the food industry, $\mathrm{CH}$ has worked to apply behavioural science to social problems with a focus on public health. Until 2018, CH headed Shift Design's Healthy Food programme, harnessing the competitive dynamics of consumer markets to deliver pro-social outcomes, such as developing products and services that catalyse changes in existing food categories leading to better diets. He now works as an independent consultant. During 2019, he worked on projects to promote healthier nutrition with the Global Alliance for Improved Nutrition (GAIN), Guy's and St Thomas' Charity, Big Society Capital, and the London Borough of Southwark. With degrees in in economics, information systems, health informatics, and public health, GS undertakes research on policies for the prevention of obesity and related non-communicable diseases. GS co-founded INFORMAS, ${ }^{76}$ a global network of public interest non-government organisations and researchers that aims to monitor, evaluate, and support public and private sector actions to improve food environments and reduce obesity and non-communicable diseases. Research by RS has spanned the monetary value of health, macroeconomic modelling of health, and the political economy of trade and trade agreements. A substantial programme of work in recent years has involved links between agriculture, the environment, and health, and public health economics in the UK and globally.

Competing interests We have read and understood BMJ policy on declaration of interests and declare the following interests: MW is funded as a scientist in the Centre for Diet and Activity Research (CEDAR), MRC Epidemiology Unit, University of Cambridge. CEDAR is a UK clinical research collaboration, public health research centre of excellence, which received funding from the British Heart Foundation, Cancer Research UK, Economic and Social Research Council, Medical Research Council (MRC), National Institute of Health Research (NIHR), and Wellcome Trust. MW is also funded by NIHR as director of its public health research funding programme. MW, with RS, holds a research grant from NIHR to evaluate the UK soft drinks industry levy; a grant from the Canadian Institutes of Health Research to fund the International Food Policy Study; and has held a grant from MRC to develop consensus on the governance of relationships between public health scientists and the food industry. MW is an expert adviser to the Food Foundation and the House of Lords Committee on Food, Poverty Health and the Environment; and a member of the Obesity Health Alliance, Independent Obesity Strategy working group. Between 2008 and 2011, DTF received funds from government, non-profits and the private sector to organise three meetings on building trust to examine the epidemic of obesity. $\mathrm{CH}$ receives no income from the commercial sector. In the period 1990-2005, CH was employed, with Nestle and Mondelez, in various commercial roles in the UK and mainland Europe. Since 2005, $\mathrm{CH}$ has been studying childhood obesity in various positions across government and the charitable sector. GS reports grants from the Australian Research Council, the National Heart Foundation of Australia, and the National Health and Medical Research Council (Australia); and GS recently conducted a study to benchmark the nutrition related policies of major food and beverage companies in Australia. GS is a researcher involved in a NHMRC-funded trial of healthy supermarket interventions in partnership with IGA (supermarket retailer), City of Greater Bendigo and VicHealth.

Provenance and peer review: Commissioned; externally peer reviewed.

This article is one of a series commissioned by The BMJ. Open access fees for the series were funded by SwissRe, which had no input into the commissioning or peer review of the articles. The BMJ thanks the series advisers, Nita Forouhi and Dariush Mozaffarian, for valuable advice and guiding selection of topics in the series.

1 Stuckler D, Nestle M. Big food, food systems, and global health. PLoS Med 2012;9:e1001242. 10.1371/journal.pmed.1001242 22723746

2 Monteiro CA, Moubarac J-C, Cannon G, Ng SW, Popkin B. Ultra-processed products are becoming dominant in the global food system. Obes Rev 2013;14(Suppl 2):21-8. 10.1111/obr.12107 24102801

3 Lobstein T, Brinsden HC. Atlas of childhood obesity. World Obesity Federation, 2019.

4 Swinburn B. Power dynamics in 21st-century food systems. Nutrients 2019;11:2544. 10.3390/nu11102544 31652523

5 Scrinis G, Monteiro CA. Ultra-processed foods and the limits of product reformulation. Public Health Nutr 2018;21:247-52. 10.1017/S1368980017001392 28703086

6 Agricultural Marketing Resource Centre. USDA value-added Ag definition. Ames, lowa, USA: Agricultural Marketing Resource Centre, lowa State University, 2019. (https://www. agmrc.org/business-development/getting-prepared/valueadded-agriculture/articles/usdavalue-added-ag-definition).

7 Swinburn BA, Kraak VI, Allender S, etal . The global syndemic of obesity, undernutrition, and climate change: the Lancet Commission report. Lancet 2019;393:791-846. 10.1016/S0140-6736(18)32822-8 30700377

8 Willett W, Rockström J, Loken B, etal . Food in the Anthropocene: the EAT-Lancet Commission on healthy diets from sustainable food systems. Lancet 2019;393:447-92. 10.1016/S0140-6736(18)31788-4 30660336

9 Breslin PAS. An evolutionary perspective on food and human taste. Curr Biol 2013;23:R409-18. 10.1016/j.cub.2013.04.010 23660364 
10 Gakidou E, Afshin A, Abajobir AA, etal. GBD 2016 Risk Factors Collaborators. Global, regional, and national comparative risk assessment of 84 behavioural, environmental and occupational, and metabolic risks or clusters of risks, 1990-2016: a systematic analysis for the Global Burden of Disease Study 2016. Lancet 2017;390:1345-422. 10.1016/S0140-6736(17)32366-8 28919119

11 Nestle M. Food politics: how the food industry influences nutrition and health. 3rd ed. University of California Press, 2013

12 Lang T, Heasman M. Food wars. Routledge, 2016.

13 Beckman J, Dyck J, Heerman KER. The global landscape of agricultural trade, 1995-2014. U.S. Department of Agriculture, Economic Research Service, 2017.

14 Vandevijvere S, Jaacks LM, Monteiro CA, etal. Global trends in ultraprocessed food and drink product sales and their association with adult body mass index trajectories. Obes Rev 2019;20(Suppl 2):10-9. 10.1111/obr.12860. 31099480

15 Fiolet T, Srour B, Sellem L, etal . Consumption of ultra-processed foods and cancer risk: results from NutriNet-Santé prospective cohort. BMJ 2018;360:k322. 10.1136/bmj.k322 29444771

16 Srour B, Fezeu LK, Kesse-Guyot E, etal . Ultra-processed food intake and risk of cardiovascular disease: prospective cohort study (NutriNet-Santé). BMJ 2019;365:11451. 10.1136/bmj.l145131142457

17 Shrimpton R, Rokx C. The double burden of malnutrition: a review of global evidence. Health, nutrition and population (HNP) discussion paper 2012. http://documents.worldbank. org/curated/en/905651468339879888/pdf/795250WPODoublO0Box037737900PUBLIC0. pdf

18 Nelson G, Bogard J, Lividini K, etal . Income growth and climate change effects on global nutrition security to mid-century. Nature Sustainability 2018:1:773-8110.1038/s41893-018-0192-z.

19 Brooks J. Fish and chips in commercial foodservice, 2016. Grimsby: Seafish, 2017. https: //www.seafish.org/media/Publications/Factsheet_-_Fish_and_Chips_in_Foodservice_ 2016.pdf

20 Centre for Diet and Activity Research. The food environment assessment tool. MRC Epidemiology Unit, 2019. www.feat-tool.org.uk

21 Simon M. Appetite for profit: how the food industry undermines our health and how to fight back. Nation Books, 2006.

22 Moodie R, Stuckler D, Monteiro C, etal. Lancet NCD Action Group. Profits and pandemics: prevention of harmful effects of tobacco, alcohol, and ultra-processed food and drink industries. Lancet 2013;381:670-9. 10.1016/S0140-6736(12)62089-3 23410611

23 Mialon M, Swinburn B, Sacks G. A proposed approach to systematically identify and monitor the corporate political activity of the food industry with respect to public health using publicly available information. Obes Rev 2015;16:519-30. 10.1111/obr.12289 25988272

24 Corporate Europe Observatory. A red light for consumer information. The food industry's $€ 1$-billion campaign to block health warnings on food. Corporate Europe Observatory, 2010.

25 Vallgårda S, Holm L, Jensen JD. The Danish tax on saturated fat: why it did not survive. Eur J Clin Nutr 2015;69:223-6. 10.1038/ejcn.2014.224 25351647

26 Tansey G, Worsley T. The food system: a guide. Earthscan Publications, 1995

27 Rutter $\mathrm{H}$, Savona N, Glonti K, etal . The need for a complex systems model of evidence for public health. Lancet 2017;390:2602-4. 10.1016/S0140-6736(17)31267-9 28622953

28 Aastrup J, Kotzab H. Forty years of out-of-stock research - and shelves are still empty. Int Rev Retail Distrib Consum Res 2010;20:147-6410.1080/09593960903498284.

29 Scarborough P, Adhikari V, Harrington RA, etal . Impact of the announcement and implementation of the UK Soft Drinks Industry Levy on sugar content, price, product size and number of available soft drinks in the UK, 2015-19: A controlled interrupted time series analysis[ISRCTN18042742]. PLoS Med 2020;17:e1003025. 10.1371/journal.pmed. 100302532045418

30 Penney $\mathrm{T}$, Adams $\mathrm{J}$, White $\mathrm{M}$. Industry reactions to the UK soft drinks industry levy: unpacking the evolving discourse from announcement to implementation (LB4). J Epidemiol Community Health 2018;72(Suppl 1):A43.

31 Burns C, Sacks G, Rayner M, Bilenkij G, Swinburn B. Correctly calculating the cost of food. Nutr Rev 2010;68:182-3, author reply 184-5. 10.1111/j.1753-4887.2010.00275.x 20384849

32 Cairns G. Evolutions in food marketing, quantifying the impact, and policy implications. Appetite 2013;62:194-7. 10.1016/.j.appet.2012.07.016 22858428

33 Augustin MA, Riley M, Stockmann R, etal . Role of food processing in food and nutrition security. Trends Food Sci Technol 2016;56:115-2510.1016/j.tifs.2016.08.005.

34 Monteiro CA, Cannon G, Levy RB, etal. Ultra-processed foods: what they are and how to identify them. Public Health Nutr 2019;22:936-41. $10.1017 /$ S 136898001800376230744710

35 Williams P. Consumer understanding and use of health claims for foods. Nutr Rev 2005;63:256-64. 10.1111/j.1753-4887.2005.tb00382.x 16121480

36 Stuckler D, McKee M, Ebrahim S, Basu S. Manufacturing epidemics: the role of global producers in increased consumption of unhealthy commodities including processed foods, alcohol, and tobacco. PLoS Med 2012;9:e1001235. 10.1371/journal.pmed. 100123522745605

37 Lang T. Food industrialisation and food power: implications for food governance. Dev Policy Rev 2003:21:555-6810.1111/j.1467-8659.2003.00223.x.

38 Muller M, Tagtow A, Roberts SL, Macdougall E. Aligning food systems policies to advance public health. $J$ Hunger Environ Nutr 2009;4:225-40. 10.1080/1932024090332119323144671

39 Sacks G, Swinburn BA, Cameron AJ, Ruskin G. How food companies influence evidence and opinion - straight from the horse's mouth. Crit Public Health 2018:28:253-610.1080/09581596.2017.1371844.

40 Porter M, Kramer MR. Creating shared value: how to reinvent capitalism - and unleash a wave of innovation and growth. Harv Bus Rev 2011;89:62-77.

41 Henriques A, Richardson J, eds. The triple bottom line. Does it all add up? $1 \mathrm{st}$ ed. Routledge, 2014

42 B Corporation. Certified B Corporation. 2019. https://bcorporation.net/

43 Jones $\mathrm{P}$, Comfort D, Hillier D. Healthy eating and the UK's major food retailers: a case study in corporate social responsibility. Br Food $J$ 2006;108:838-4810.1108/00070700610702091.

44 Imamura F, Micha R, Khatibzadeh S, etal. Global Burden of Diseases Nutrition and Chronic Diseases Expert Group (NutriCoDE). Dietary quality among men and women in 187 countries in 1990 and 2010: a systematic assessment. Lancet Glob Health 2015;3:e132-42. 10.1016/S2214-109X(14)70381-X 25701991
45 Eccles RG, loannou I, Serafeim G. The impact of corporate sustainability on organizational processes and performance. Manage Sci 2014;60:2835-5710.1287/mnsc.2014.1984.

46 Ni Mhurchu C, Brown R, Jiang Y, Eyles H, Dunford E, Neal B. Nutrient profile of 23596 packaged supermarket foods and non-alcoholic beverages in Australia and New Zealand. Public Health Nutr 2016;19:401-8. 10.1017/S1368980015000968 2586888

47 Remnant J, Adams J. The nutritional content and cost of supermarket ready-meals. Cross-sectional analysis. Appetite 2015;92:36-42. 10.1016/..appet.2015.04.069 25963106

8 Ejlerskov KT, Stead M, Adamson A, White M, Adams J. The nature of UK supermarkets' policies on checkout food and associations with healthfulness and type of food displayed: cross-sectional study. Int J Behav Nutr Phys Act 2018;15:52 10.1186/s12966-018-0684-2 29891005

49 Rivlin G. Rigged: supermarket shelves for sale. In: Almy J, Wootan MG, eds. CSPI Nutrition Policy Project Report, 2016. https://cspinet.org/sites/default/files/attachment/CSPI_Rigged_ 4_small.pdf

50 The Food Foundation. Peas Please. London: The Food Foundation, 2017. https:// foodfoundation.org.uk/about-peas-please/

51 Knai C, Petticrew M, Durand MA, etal . Has a public-private partnership resulted in action on healthier diets in England? An analysis of the Public Health Responsibility Deal food pledges. Food Policy 2015;54:1-1010.1016/j.foodpol.2015.04.002.

52 He FJ, Brinsden HC, MacGregor GA. Salt reduction in the United Kingdom: a successful experiment in public health. $J$ Hum Hypertens 2014:28:345-52. 10.1038/jhh.2013.105 24172290

53 Department for Environment Food and Rural Affairs. Family food 2012. National Statistics, 2013. https://assets.publishing.service.gov.uk/government/uploads/system/uploads/ attachment_data/file/265243/familyfood-2012report-12dec13.pdf

54 Nguyen BT, Powell LM. The impact of restaurant consumption among US adults: effects on energy and nutrient intakes. Public Health Nutr 2014;17:2445-52. 10.1017/S1368980014001153 25076113

55 Nago ES, Lachat CK, Dossa RA, Kolsteren PW. Association of out-of-home eating with anthropometric changes: a systematic review of prospective studies. Crit Rev Food Sci Nutr 2014;54:1103-16. 10.1080/10408398.2011.627095 24499144

56 Adams J, Goffe L, Brown T, etal . Frequency and socio-demographic correlates of eating meals out and take-away meals at home: cross-sectional analysis of the UK national diet and nutrition survey, waves 1-4 (2008-12). Int J Behav Nutr Phys Act 2015;12:51. 10.1186/s12966-015-0210-8 25889159

57 Robinson E, Jones A, Whitelock V, Mead BR, Haynes A. (Over)eating out at major UK restaurant chains: observational study of energy content of main meals. $B M J$ 2018:363:k4982. 10.1136/bmj.k4982 30541906

58 Roberts SB, Das SK, Suen VMM, etal . Measured energy content of frequently purchased restaurant meals: multi-country cross sectional study. BMJ 2018;363:k4864. 10.1136/bmj.k4864 30541752

59 Hillier-Brown FC, Summerbell CD, Moore HJ, etal . A description of interventions promoting healthier ready-to-eat meals (to eat in, to take away, or to be delivered) sold by specific food outlets in England: a systematic mapping and evidence synthesis. BMC Public Health 2017:17:93. 10.1186/s12889-016-3980-2. 28103846

60 Hillier-Brown FC, Summerbell CD, Moore HJ, etal . The impact of interventions to promote healthier ready-to-eat meals (to eat in, to take away or to be delivered) sold by specific food outlets open to the general public: a systematic review. Obes Rev 2017;18:227-46. 10.1111/obr.12479 27899007

61 Crockett RA, King SE, Marteau TM, etal . Nutritional labelling for healthier food or non-alcoholic drink purchasing and consumption. Cochrane Database Syst Rev 2018;2:CD009315. 10.1002/14651858.CD009315.pub2 29482264

62 Zlatevska N, Neumann N, Dubelaar C. Mandatory calorie disclosure: a comprehensive analysis of its effect on consumers and retailers. $J$ Retailing 2018;94:89-10110.1016/j.jretai.2017.09.007.

63 Hollands GJ, Shemilt I, Marteau TM, etal . Portion, package or tableware size for changing selection and consumption of food, alcohol and tobacco. Cochrane Database Syst Rev 2015;9:CD011045. 10.1002/14651858.CD011045.pub2 26368271

64 Goffe L, Hillier-Brown F, Doherty A, etal . Comparison of sodium content of meals served by independent takeaways using standard versus reduced holed salt shakers: cross-sectional study. Int J Behav Nutr Phys Act 2016;13:102. 10.1186/s12966-016-0429-z 27670137

65 Cornelsen L, Mytton OT, Adams J, etal . Change in non-alcoholic beverage sales following a 10-pence levy on sugar-sweetened beverages within a national chain of restaurants in the UK: interrupted time series analysis of a natural experiment. J Epidemiol Community Health 2017;71:1107-12. 10.1136/jech-2017-209947 29038317

66 Welch S. National food brands increasingly seek small food companies to reinvent themselves. Crain's Detroit Business. Detroit, ILL. Crain Communications,2016.

67 Yau A, Adams J, Monsivais P. Time trends in adherence to UK dietary recommendations and associated sociodemographic inequalities, 1986-2012: a repeated cross-sectional analysis. Eur J Clin Nutr 2019;73:997-1005. 10.1038/s41430-018-0347-z 30446763

68 Bottemiller Evich H, Boudreau C. The big Washington food fight. POLITICO, 2017. https: //www.politico.com/story/2017/11/26/food-lobby-consumer-tastes-washington-190528.

69 Haddad L. Reward food companies for improving nutrition. Nature 2018;556:19-22. 10.1038/d41586-018-03918-7 29620753

70 Battilana J, Pache A-C, Sengul M, Kimsey M. The dual-purpose playbook. Harv Bus Rev 2019;97:124-33. https://hbr.org/2019/03/the-dual-purpose-playbook

71 Malhi L, Karanfil O, Merth T, Acheson M, Palmer A, Finegood DT. Places to intervene to make complex food systems more healthy, green, fair, and affordable. $J$ Hunger Environ Nutr 2009;4:466-76. 10.1080/19320240903346448 23173029

72 Department of Health and Social Care. Childhood obesity: a plan for action, chapter 2 . HM Government, 2018. https://www.gov.uk/government/publications/childhood-obesitya-plan-for-action-chapter-2

73 Lencucha R, Dubé L, Blouin C, Hennis A, Pardon M, Drager N. Fostering the catalyst role of government in advancing healthy food environments. Int $\mathrm{J}$ Health Policy Manag 2018;7:485-90. 10.15171/ijhpm.2018.10 29935125

74 Food Foundation, Food Climate Research Network. Plating up progress. Part 2: 'Must-have metrics. Food Foundation, 2019. https://fcrn.org.uk/sites/default/files/plating-up-progress report2_digital.pdf

75 Kauer I, Marije Boomsma, Paul Vos, Simona Kramer, Ellen Poolman, Fiona Kirk, et al. Access to Nutrition Index. Global Index 2018. Access to Nutrition Foundation, 2018. https: //www.accesstonutrition.org/

76 Swinburn B, Vandevijvere S. INFORMAS (International Network for Food and Obesity/non-communicable Diseases (NCDs) Research, Monitoring and Action Support). 
School of Population Health, University of Auckland, 2019. https://www.informas.org/ about-informas/

77 World Health Organization. WHO Framework Convention on Tobacco Control. World Health Organization, 2003. https://apps.who.int/iris/bitstream/handle/10665/42811/ 9241591013.pdf;jsessionid=ACODOFB84374FD5662A7BD2720793B3E? sequence=1

78 Johnston LM, Finegood DT. Cross-sector partnerships and public health: challenges and opportunities for addressing obesity and noncommunicable diseases through engagement with the private sector. Annu Rev Public Health 2015;36:255-71.

with the private sector. Annu Rev Public Health 2015;36

79 Solomon RC, Flores F. Building trust. In business, politics, relationships, and life. Oxford University Press, 200310.1093/0195161114.001.0001.

80 Lang T. Reshaping the food system for ecological public health. $J$ Hunger Environ Nutr 2009;4:315-35. 10.1080/19320240903321227 23144673

81 Bua A, Escobar O. Participatory-deliberative processes and public policy agendas: lessons for policy and practice. Policy Design and Practice 2018;1:126-40. 10.1080/25741292.2018.1469242.

82 Department for Environment Food and Rural Affairs. National Food Strategy. DEFRA, 2019. https://www.nationalfoodstrategy.org/
83 Cullerton K, Adams J, Forouhi N, Francis O, White M. What principles should guide interactions between population health researchers and the food industry? Systematic scoping review of peer-reviewed and grey literature. Obes Rev 2019;20:1073-84. 10.1111/obr.12851 30968553

84 Cullerton K, Adams J, Francis O, Forouhi N, White M. Building consensus on interactions between population health researchers and the food industry: two-stage, online, international Delphi study and stakeholder survey. PLoS One 2019;14:e221250. 10.1371/journal.pone.0221250 31437189

(C) Author(s) (or their employer(s)) 2019. Re-use permitted under CC BY-NC. No commercial re-use. See rights and permissions. Published by

BMJ.http://creativecommons.org/licenses/by-nc/4.0/This is an Open Access article distributed in accordance with the Creative Commons Attribution Non Commercial (CC BY-NC 4.0) license, which permits others to distribute, remix, adapt, build upon this work non-commercially, and license their derivative works on different terms, provided the original work is properly cited and the use is non-commercial. See: $\mathrm{http}: / / c r e a t i v e c o m m o n s$. org/licenses/by-nc/4.0\%. 


\section{Table}

Table $1 \mid$ Key characteristics of the commercial food system, actions to deal with challenges to population health, and unanswered research questions

System characteristics Consequences $\quad$ Actions required unanswered research questions

Year on year growth

Publicly listed companies are motivated to grow owing to continual pressure to increase short term profit
A strong focus on short termism and sustainability

A lack of attention to costly economic, environmental, and health externalities generated

Expectations of unsustainable growth that lead to a relentless focus on adding value by unhealthy processing, aggressive marketing, and push-back on regulation

A radical reset of the business model to What are the regulatory mechanisms that A shift towards a multidimensional sustainable growth?

valuation of companies, new accounting How can a cultural shift be achieved towards methods, and development of metrics to a new conception of businesses as generating measure social impact both social and economic value?

Alternative business models, driven by What successful alternative (eg, social) "triple bottom line" and "circular economy" business models exist that can be applied to principles, which are being discussed by the food sector?

major international organisations and

How can policy makers and the commercial food sector be enticed to accept such new business models?

How can the social impact of such models be successfully measured and rewarded in the market?

\section{Focus on processing}

Processing and associated marketing add value to foodstuffs, thus maximising income and profits
Large numbers of highly convenient, shelf stable, affordable food products, often nutritionally poor and associated with risk of non-communicable diseases Processed foods, engineered to appeal to human taste preferences, have become the norm in many diets worldwide

Processed foods are marketed as aspirational

\section{Manipulation of demand} through marketing of processed foods

Aggressive, and sometimes predatory, marketing tactics unacceptably promote sales processed foods, particularly to become normalised in many societies children and marginalised populations

\section{Marketing is increasingly pursued} through multiple media using advertising, and by manipulation of product, price, and placement of products

Highly effective marketing of processed (20) advertisements for processed foods

Commercial sector influence Corporate political activity involves a and push-back on policy development and implementation Commercial companies regularly seek to, and achieve, influence on policy making for unhealthy foods, and use other tactics to influence public debate
Increase of taxes on processed foods, leading to an increase in the price differential between healthy and less healthy foods; VAT or specific taxes could be used

Introduction of subsidies on healthier foods to maximise the value of this approach

Regulation of marketing to reduce pressure on citizens to consume processed food products Regulation of marketing to apply to placement (eg, restriction on advertising processed foods on London's transport system), timing, media, and target audience (eg, restrictions on during children's TV), content of marketing (eg, restricting use of product endorsement by cartoon characters or celebrities), and restriction on the use of price promotions (eg, in supermarkets or fast food takeaways)

Countering of corporate political activity What are the emerging tactics used by the

What foods could be taxed or subsidised in the interests of population health?

What are the barriers and opportunities to achieving such fiscal policies?

What are the views of policy makers and the food sector of such regulatory mechanisms? What effects could such policies have? How can such fiscal policies be designed to avoid legal challenge and repeal?

How could marketing of unhealthy foods most effectively be reduced?

What are the levers to achieve such changes? What are the legal and practical barriers to

achieving reductions in marketing of unhealthy foods?

What are the views of policy makers and the food sector of regulatory or other mechanisms to reduce marketing of unhealthy food? Would regulatory measures have the support of the public? by researchers and authorities to expose commercial food sector to influence policy on such tactics, requiring transparency of all unhealthy foods?

activities under law, legal defence against How do the public and policy makers view challenges to policy development and these tactics? implementation, stricter regulation in place of voluntary codes of practice, and stricter standards for governance of What key strategies can be employed to counter such tactics and develop more constructive dialogue between policy makers and the commercial food system?

What are the barriers to reducing the use of such tactics by the food industry, and how can these be overcome? number of widely used tactics to ensu that regulation is avoided, including: framing of information to suit corporate objectives (eg, manipulation of science) providing financial incentives to policy makers; building constituency among policy makers, community groups, and health organisations; adopting lega strategies to oppose public health measures; making extensive use of voluntary industry codes of practice in place of government regulation; "conversation-changing" publicity; and making efforts to fragment and destabilise groups likely to counter corporate arguments 
Table 1 (continued)

\begin{tabular}{|c|c|}
\hline System characteristics & Consequences \\
\hline $\begin{array}{l}\text { Support for commercial } \\
\text { sector corporate political } \\
\text { activity from think tanks, the }\end{array}$ & $\begin{array}{l}\text { Prevailing "anti-nanny state" rhetoric } \\
\text { about regulation of the commercial fooc } \\
\text { sector }\end{array}$ \\
\hline media, and politicians & Scaremongering in response to public \\
\hline $\begin{array}{l}\text { Close links with key } \\
\text { organisations that aim to shape } \\
\text { public and political discourse } \\
\text { lead to framing of arguments } \\
\text { that support neo-liberal policies }\end{array}$ & $\begin{array}{l}\text { debate (eg, government policy } \\
\text { consultations) on regulation in trade } \\
\text { press and public media }\end{array}$ \\
\hline
\end{tabular}

Market saturation and control Companies constantly look for by a small number of businesses which compete for market share

High concentration of market ownership in the commercial food sectors, a consequence and driver of competition and opportunities to gain market share through product innovation, increased sites on the high street, and increased opportunities for marketing through diverse channels unsustainable growth opportunities to reduce costs and secure

on healthier food, and for scaling up of entrants that cannot operate efficiencies large, healthier food businesses of scale struggle to survive

Lack of diversification in businesses controlling the system dampens innovation and productivity, which means that shifts to healthier and more sustainable foods are slower to arrive

Food environments are dominated by appealing, low cost, non-perishable, low nutrient, high calorie foods, resulting in unhealthy choices

Asymmetry of access to A lack of information about what is in

information between the food system and wider society Information about the nature and healthiness of foods is not routinely made available to the public or professionals
A lack of information about what is in food and how it is produced prevents
public, professionals, investors, and governments from making informed choices and using their agency to demand healthier food

Supply shapes demand more than demand shapes supply
Set new government standards for information available on all foods, including origin, processing, carbon co and nutritional content that go beyond minimum standards

Ensure transparency and new standards of governance in the commercial food system.

\section{Key unanswered research questions}

What are the channels through which the commercial food sector seeks support for the prevailing business model? in the public interest, as well as the social transition to a healthier and more sustainable output

Identify the most effective channels of communication for these arguments

Explore legal means to counter such as supermarket slotting or listing fees

Stronger governmental support for innovative start-up companies that focus What are the levers that might help to change the conversation?

What are the barriers that might lead to entrenchment?

What are the key counter arguments and means of communication that can be used by public health and policy teams?

How does the business environment restrict competition from healthier food companies? What are the levers for change to the present system?

What are the views of policy makers and the food sector on reforming the current regulatory and business environments?

What effects could such changes have?

\begin{tabular}{|c|c|c|c|}
\hline $\begin{array}{l}\text { Costs can be externalised, } \\
\text { and government and the } \\
\text { public implicitly accept and } \\
\text { support this through NHS } \\
\text { investment, farmer subsidies, } \\
\text { and benefit payments for low } \\
\text { paid workers } \\
\text { The commercial sector does not } \\
\text { pay the full, long term costs of } \\
\text { environmentally damaging } \\
\text { production in a low wage } \\
\text { economy and consumption of } \\
\text { unhealthy foods }\end{array}$ & $\begin{array}{l}\text { Processed foods are artificially cheap, } \\
\text { leading to imbalances of price across the } \\
\text { food basket } \\
\text { Convenient, healthy diets from } \\
\text { sustainable food systems are more } \\
\text { expensive } \\
\text { High carbon cost, biodiversity loss, and } \\
\text { poor population health }\end{array}$ & $\begin{array}{l}\text { Governments should require food } \\
\text { companies to incorporate external costs } \\
\text { of food production for each product } \\
\text { individually, such that the cost of } \\
\text { processed and less healthy foods would } \\
\text { increase proportionately more than the } \\
\text { cost of raw produce and more healthy } \\
\text { foods } \\
\text { Subsidies that reinforce externalities } \\
\text { should be eliminated }\end{array}$ & $\begin{array}{l}\text { How can the external costs of food be } \\
\text { calculated in ways that would inform policy } \\
\text { and drive a rebalancing of the system? } \\
\text { What are the levers that could lead to } \\
\text { incorporating the external costs of foods at a } \\
\text { system level? } \\
\text { How receptive is government and the food } \\
\text { sector to such a scheme? } \\
\text { How would the public view such a scheme? } \\
\text { What effects could such a scheme have on } \\
\text { health, environment, economy, and dietary } \\
\text { inequalities? }\end{array}$ \\
\hline
\end{tabular}

What information is available to the public and professionals?

What information do they want?

How do they want to receive information? Which formats of labels will be most effective in (a) informing consumers, and (b) stimulating healthier reformulation?

What levers are there to stimulate change in information asymmetry?

What are the views of policy makers and the food sector about rebalancing information asymmetry?

What effects could mandated labelling have on food production, reformulation, and consumption? and drive a rebalancing of the system? What are the levers that could lead to system level? sector to such a scheme?

What effects could such a scheme have on inequalities? 
Table 1 (continued)

System characteristics

The food system is unpredictable, emergent and self-organising

multiple complex adaptive

systems

\section{Consequences}

Actions required

The food system adapts within its current Identify levers for change that deal with multiple levels for intervention, including deeply held beliefs (eg, in the need for continual growth), the goals the system is trying to achieve, and structural components of the whole system

Focus on powerful, not weak, levers for change

Introduce disruptive innovations that may lead to a period of chaos but could result in the lasting and substantial change that will be needed

Poor goal alignment results in all the above challenges, and is a consequence

Poor goal alignment d of their continuation in a vicious cycle

The goals and drivers of many elements of the commercial food system are poorly aligned with the goals of population health, environmental sustainability, Companies are evaluated on a achieving economic, health, and sustainability goals easier; this requires a substantial change in approach unidimensional scale (short term profit), Voluntary or regulatory measures, which rather than multidimensionally (profit and could help to shift the food system social, environmental, and health impact) towards a better balance

Key unanswered research questions

What are the rules that bind complex, adaptive food systems?

Who are the key people who need to be influenced to change the food system? What are the key beliefs and structures that will need to change?

What are the levers that could be used to achieve such changes?

What health and other effects might be achieved by such changes to the system? What are the views of the public, policy makers, and the food sector about disruptive innovation?

and equity 


\section{Figures}

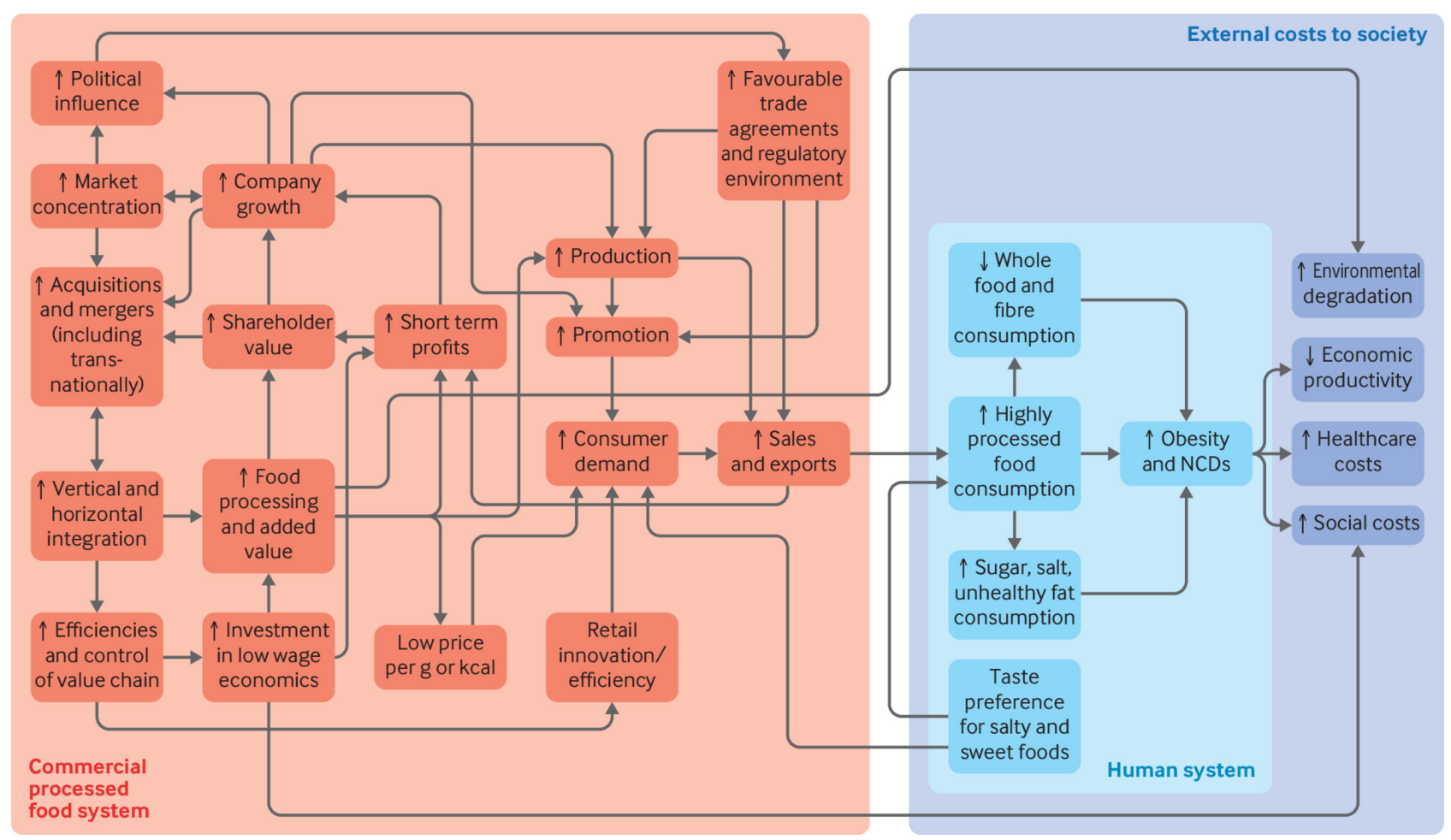

Fig 1 The commercial processed food system, influences on human health, and external costs to society (NCDs=non-communicable diseases) 


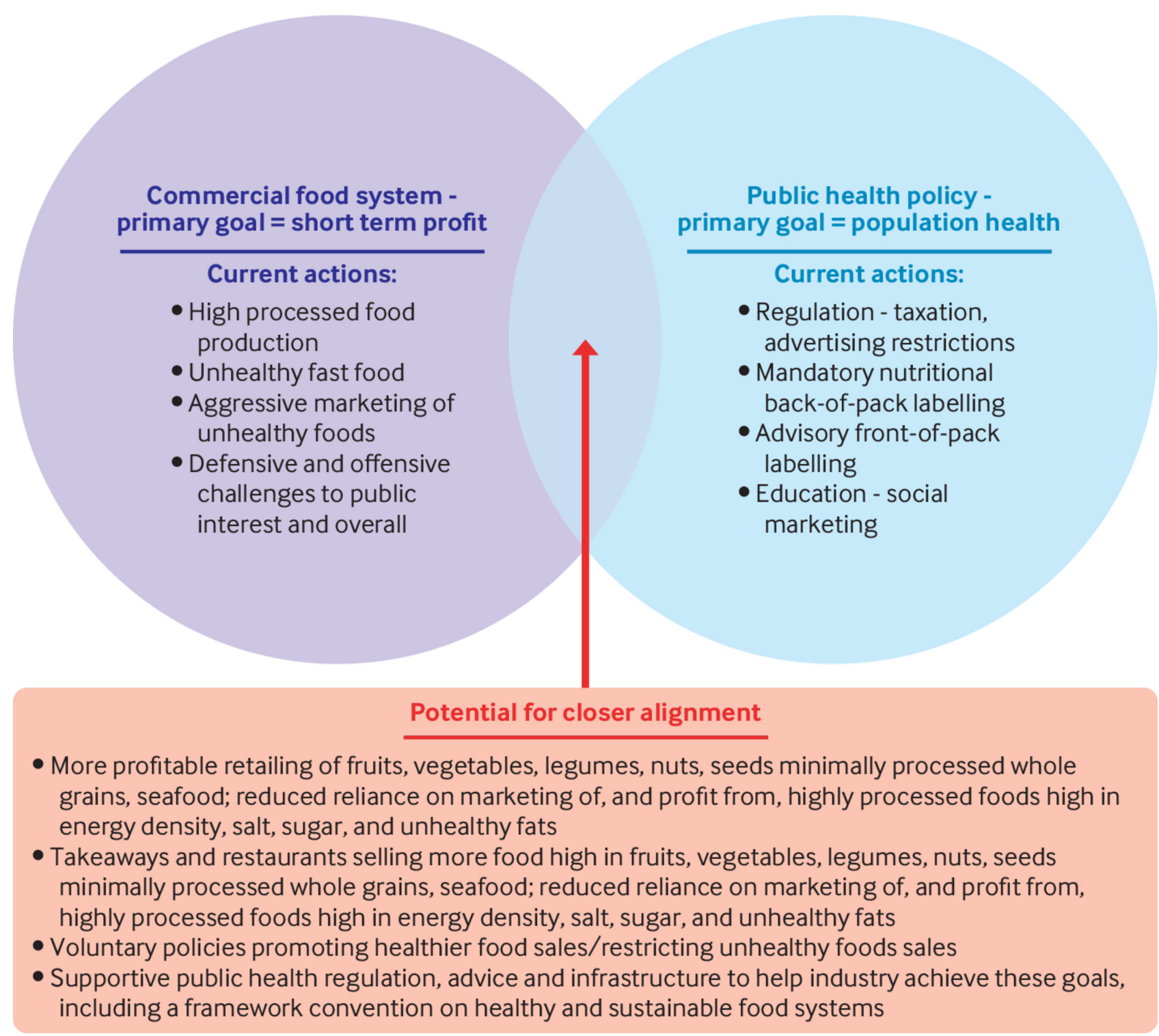

Fig 2 Goals, actions, and alignment of the commercial food system and public health 